BUCHREIHE DER ANGLIA

ZEITSCHRIFT FUR ENGLISCHE PHILOLOGIE

1. BAND

W. F. S CHIRMER, LYDGATE 




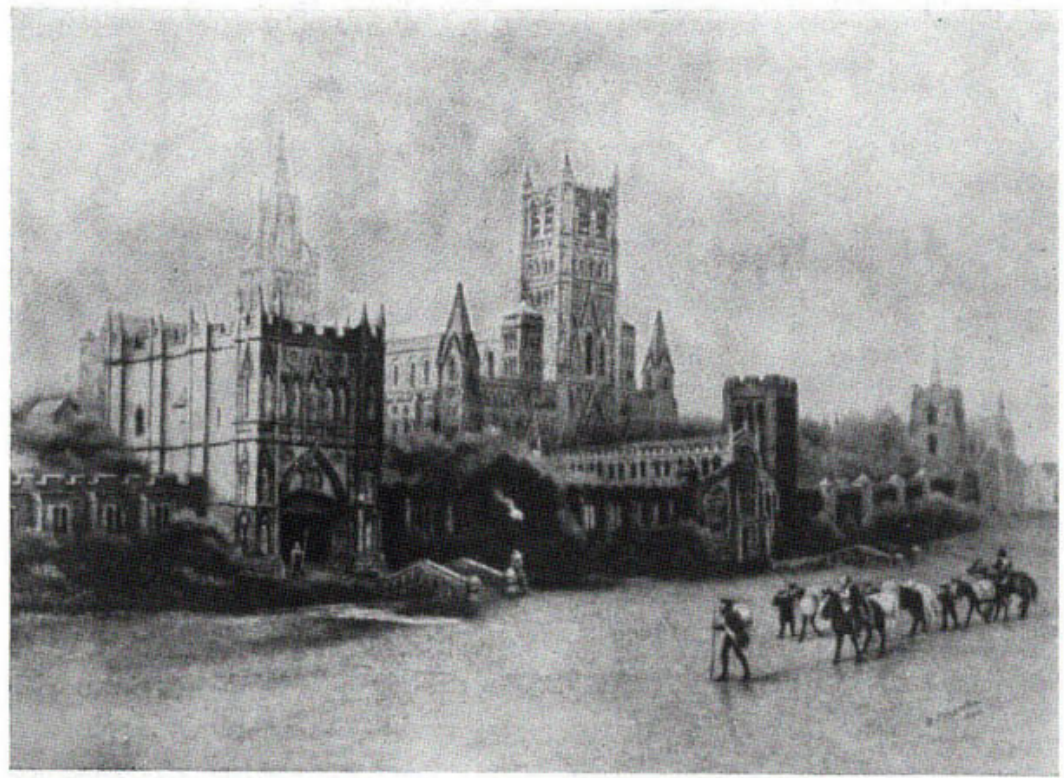

Westansicht des Klosters Bury St. Edmunds 


\section{JOHN LYDGATE}

Ein Kulturbild

aus dem 15. Fabrbundert

VON

WALTER F. SCHIRMER

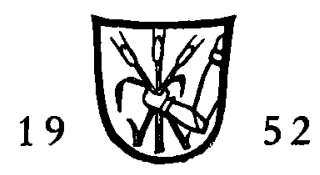

MAX NIEMEYER VERLAG / TÜBINGEN 
Gedrudkt mit Unterstützung der Deutschen Forschungsgemeinschaft

Copyright 1952 by Max Niemeyer Verlag Tübingen

Bildwiedergaben mit Erlaubnis des British Museum, London und der Oxford University Press

Drudk: Tübinger Chronik, Druckerei- und Verlagsgenossenschaft eGmbH, Tübingen 